\title{
CAIXA DA NATUREZA: UMA PROPOSTA PARA EDUCAÇÃO AMBIENTAL EM
} ESPAÇOS NÃO-FORMAIS

\author{
NATURE'S BOX: A PROPOSAL FOR ENVIRONMENTAL EDUCATION IN NON- \\ FORMAL SPACES
}

\section{CAJA DE LA NATURALEZA: UNA PROPUESTA DE EDUCACIÓN AMBIENTAL EN ESPACIOS NO FORMALES}

Ercilene do Nascimento Silva de Oliveira ${ }^{1}$ (i) 9

Sammya Danielle Florencio dos Santos $^{2}$ (D) 9

Fabrícia Souza da Silva ${ }^{3}$ (D) 9

Augusto Fachín Terán ${ }^{4}$ (i)

\begin{abstract}
RESUMO
O presente estudo trabalha a Educação Ambiental, tencionando contribuir para a formação de professores e uma ampla compreensão das diversas dimensões que abrangem esta temática. Neste sentido, este artigo discute como desenvolver a Educação Ambiental fora do ambiente da sala de aula, utilizando espaços não-formais para possibilitar uma aprendizagem significativa, explorando os recursos e elementos naturais disponíveis para o ensino. O estudo tem como objetivo compreender como se dá a difusão da Educação Ambiental nos espaços educacionais por meio da aplicação de uma atividade prática de campo denominada "Caixa da Natureza". No que se refere aos aspectos metodológicos, a pesquisa apresenta uma abordagem qualitativa descritiva, tendo sua fundamentação filosófica norteada pelas premissas de Merleau-Ponty. O local utilizado foi o Bosque da Ciência, do Instituto Nacional de Pesquisas da Amazônia (INPA). Os sujeitos participantes foram 58 universitários, da disciplina de Educação Ambiental, do curso de Licenciatura em Pedagogia, de uma instituição pública de Ensino Superior de Manaus, Amazonas. Uma caixa de papelão foi confeccionada e posicionada em lugar estratégico, para que, ao fim da atividade prática, os participantes pudessem deixar suas respostas sobre uma questão formulada. Para analisar os dados tomamos como base a Análise de Conteúdo de Bardin. Os resultados obtidos com a realização da pesquisa apontam que a "Caixa da Natureza" despertou nos
\end{abstract}

\footnotetext{
${ }^{1}$ Mestranda do Programa de Pós-Graduação em Educação e Ensino de Ciências na Amazônia (PPGEEC), pela Universidade do Estado do Amazonas (UEA). Membro do GEPECENF. Bolsista FAPEAM, Manaus, Amazonas, Brasil. Endereço: Avenida Djalma Batista, 2470, Chapada, Manaus, Amazonas, Brasil, CEP: 69050-010. E-mail: ercilene.oliveira@gmail.com.

${ }^{2}$ Mestranda do Programa de Pós-Graduação em Educação e Ensino de Ciências na Amazônia (PPGEEC), pela Universidade do Estado do Amazonas (UEA). Professora da Secretaria Municipal de Educação de Manaus (SEMED). Membro do GEPECENF. Bolsista FAPEAM, Manaus, Amazonas, Brasil. Endereço: Avenida Djalma Batista, 2470, Chapada, Manaus, Amazonas, Brasil, CEP: 69050-010. E-mail: sammyad.santos@gmail.com.

${ }^{3}$ Mestra em Educação e Ensino de Ciências na Amazônia, pela Universidade do Estado do Amazonas (UEA). Professora da Secretaria Municipal de Educação de Manaus (SEMED). Membro do GEPECENF, Manaus, Amazonas, Brasil. Endereço: Avenida Djalma Batista, 2470, Chapada, Manaus, Amazonas, Brasil, CEP: 69050 010. E-mail: fabriciasilva.mestrado@gmail.com.

${ }^{4}$ Doutor pelo Instituto Nacional de Pesquisas da Amazônia (INPA). Professor do curso de Pedagogia e do Programa de Pós-Graduação em Educação e Ensino de Ciências na Amazônia (PPGEEC), pela Universidade do Estado do Amazonas (UEA), Manaus, Amazonas, Brasil. Líder do GEPECENF. Endereço: Avenida Djalma Batista, 2470, Chapada, Manaus, Amazonas, Brasil, CEP: 69050-010. E-mail: fachinteran@yahoo.com.br.
} 
estudantes sentimentos e atitudes em relação ao meio ambiente, possibilitando uma reflexão sobre suas futuras práticas para trabalhar a Educação Ambiental em espaços não-formais de aprendizagem.

Palavras-chave: Educação Ambiental. Formação de Professores. Elementos Naturais. Espaços nãoformais.

\begin{abstract}
Working with Environmental Education in the training of teachers is essential to train educators who understand the different dimensions that cover this theme. Therefore, working with Environmental Education outside the classroom, using non-formal spaces, enables meaningful learning by exploring the natural resources and elements available for teaching. This study aims to understand how the disclosure of Environmental Education in educational spaces occurs through the application of a practical field activity called "Nature's Box". Concerning the methodological aspects, this research presents a descriptive qualitative approach, with a philosophical foundation guided by the premises of Merleau-Ponty. The place that we used was the Science Forest of the National Institute of Amazonian Research (INPA). The participating subjects were 58 undergraduate Pedagogy students attending the Environmental Education course of a public higher education institution in Manaus, Amazonas. A cardboard box was made and placed in a strategic place so that at the end of the practical activity, the participants could leave their answers on a question asked. We used Bardin's Content Analysis for data analysis. The results reveal that the presented proposal aroused in the students feelings and attitudes towards the environment, allowing a reflection on their future practices to work on Environmental Education in non-formal learning spaces.
\end{abstract}

Keywords: Environmental Education. Teacher Training. Nature Box. Non-formal spaces.

\title{
RESUMEN
}

Trabajar con Educación Ambiental en la formación de docentes es fundamental para formar educadores que comprendan las diferentes dimensiones que cubren este tema. Por lo tanto, trabajar con Educación Ambiental fuera de la sala de clase, utilizando espacios no formales, permite un aprendizaje significativo al explorar los recursos naturales y los elementos disponibles para la enseñanza. Este estudio tiene como objetivo comprender cómo se da la divulgación de la Educación Ambiental en los espacios educativos mediante la aplicación de una actividad práctica de campo denominada "Caja de la Naturaleza". En cuanto a los aspectos metodológicos, esta investigación presenta un enfoque cualitativo descriptivo, con un fundamento filosófico guiado por las premisas de Merleau-Ponty. El lugar que usamos fue el Bosque de la Ciencia del Instituto Nacional de Investigaciones Amazónicas (INPA). Los sujetos participantes fueron 58 estudiantes de pregrado en Pedagogía del curso de Educación Ambiental de una institución pública de educación superior en Manaus, Amazonas. Se confeccionó una caja de cartón y se colocó en un lugar estratégico para que, al finalizar la actividad práctica, los participantes pudieran dejar sus respuestas a una pregunta formulada. Usamos el análisis de contenido de Bardin para el análisis de datos. Los resultados revelan que la propuesta presentada despertó en los estudiantes sentimientos y actitudes hacia el medio ambiente, permitiendo una reflexión sobre sus prácticas futuras para trabajar la Educación Ambiental en espacios de aprendizaje no formal.

Palabras clave: Educación ambiental. Formación de profesores. Caja de la naturaleza. Espacios no formales. 


\section{INTRODUÇÃO}

A natureza é tema de debates globais desde que o planeta se viu ameaçado pela ação humana em seu processo de poluição e degradação do ecossistema mundial. Em especial, no Brasil, com a criação, em 1999, da Política Nacional de Educação Ambiental - PNEA, o poder público buscou mecanismo legais para nortear os processos relacionados à Educação Ambiental (EA). Em seu Artigo $3^{\circ}$, ao destacar ser a EA um processo mais amplo, determina em seu Inciso II, que as instituições educativas devem promover a Educação Ambiental de forma integrada aos programas educacionais que desenvolvem (BRASIL, PNEA, 1999, p. 1).

Neste sentido, Cornell (2008), reforça a necessidade de envolver o indivíduo em ambientes cercados por questões ambientais, a fim de possibilitar a compreensão do tema, "pois através do homem, a Natureza é capaz de observar e desfrutar de si mesma, em sua forma mais completa e intensa" (CORNELL, 2008, p. 181). Partindo da ideia do autor, reforçamos o entendimento do sujeito histórico de Freire (2019) e sua relação com o mundo presente, tendo por base as vivências passadas, pois somente a experiência possibilitará o exercício do pensamento reflexivo, tão necessário nas questões ambientais.

Reigota (2002, p. 134), nos faz ponderar sobre a necessidade de se descontruir as representações sociais, a fim de construir novos saberes e, sendo assim, o processo pedagógico no caminho da Educação Ambiental é uma perspectiva a ser considerada em todos os níveis educacionais. "A melhor forma de aprender é combinando, equilibradamente, atividades, desafios e informações contextualizadas” (MORAN, 2015, p. 17). Do pensamento do autor, auferimos para a emergência de se fazer um ensino, onde o aprendiz seja o condutor de seu próprio conhecimento. Neste contexto, as metodologias ativas são fundamentais para implantar as práticas de Educação Ambiental, conduzindo o indivíduo à problematização do tema, no contexto social de sua realidade.

A fim de relacionar o ensino formal, das instituições escolares, com os ambientes educativos, fora da sala de aula, existem os espaços não-formais de Educação, nos quais, segundo Jacobucci (2008) é possível o público aproximar-se do conhecimento produzido pela Ciência em locais abertos à visitação. Estes ambientes, no entendimento de Marandino (2017), são instituições que possuem projetos estruturados com intencionalidades educativas definidas.

O Bosque da Ciência (BC), do Instituto Nacional de Pesquisas da Amazônia - INPA, é um destes locais, onde a pesquisa, o entretenimento e a Educação caminham lado a lado, no intuito de promover a difusão científica dos estudos amazônicos. Neste espaço, é possível 
projetar aulas, passeios e práticas educativas com estudantes da Educação Infantil ao Ensino Superior.

Diante disto, com a finalidade de buscar alternativas pedagógicas com modelos ativos de aprendizagem, além de produzir conteúdo para disseminar no meio acadêmico, apresentamos este estudo, que teve como objetivo compreender como se dá a difusão da Educação Ambiental em espaços educativos por meio da aplicação de uma atividade prática de campo denominado "Caixa da Natureza". A referida prática foi elaborada, tendo como justificativa a importância de desenvolver atividades que despertem, nos educandos, o interesse em trabalhar a Educação Ambiental nos espaços educativos de forma mais dinâmica, despertando sentimentos e atitudes benéficas em defesa do meio ambiente.

\section{REFERENCIAL TEÓRICO}

\subsection{Um olhar sobre a Educação Ambiental}

"A questão ambiental demorou muito tempo até alcançar visibilidade no cenário mundial, pois o meio ambiente era visto como uma temática pouco relevante, perante os problemas sociais, culturais e econômicos" (RUFINO; CRISPIM, 2015, p. 1). A Educação Ambiental (EA) era um assunto para o qual a sociedade não dava muita importância, sendo que a preocupação com a natureza restringia-se a alguns grupos de estudiosos, entre os quais os cientistas, os ambientalistas e os professores. Assim, por muito tempo, os problemas ambientais ficaram esquecidos na sociedade, em virtude de não serem vistos como prioridade no contexto mundial.

Foi somente a partir do século XX, em meados das décadas de 60 (sessenta) e 70 (setenta), quando começaram a surgir os primeiros sinais de uma crise considerada socioambiental, que a sociedade em geral começou a demonstrar certo interesse nos assuntos relacionados à temática ambiental.

Nesta perspectiva, o livro "Silent Spring” (Primavera Silenciosa), da bióloga Rachel Carson, lançado em outubro de 1962, trouxe grandes contribuições para esta mudança de pensamento. Neste livro, a autora faz um alerta mundial sobre o agravamento dos "impactos ambientais, causados pelo uso de pesticidas e poluentes químicos, bem como suas consequências na perda da qualidade de vida dos ecossistemas e da população" (RUFINO; CRISPIM, 2015, p. 3). Posteriormente, o livro tornou-se um clássico na história do movimento 
ambientalista, influenciando, indiretamente, a criação do Clube de Roma, formado por cientistas de diversas áreas do conhecimento, cujo objetivo era possibilitar a discussão sobre a crise ambiental mundial, que se agravava cada vez mais.

Dentre os acontecimentos que sinalizavam a eminente destruição do meio ambiente, podemos citar o vazamento de gás tóxico na cidade de Bhopal, na Índia, em 1984, que deixou mais de 8 (oito) mil pessoas mortas, bem como a explosão na usina nuclear de Chernobyl, na Ucrânia, em 1986, quando uma explosão e um incêndio lançaram grandes quantidades de partículas radioativas na atmosfera, a qual espalhou-se por boa parte da antiga União Soviética e da Europa Ocidental. Este acidente foi considerado o pior da história em termos de custos, mortes resultantes e contaminação do ambiente (TELLES; BRAGA, 2004).

No Brasil, na década de 80 (oitenta), na Amazônia, a sociedade presenciava o desmatamento desenfreado da floresta e a construção da Usina Hidrelétrica de Balbina, situada no município de Presidente Figueiredo, localizado no Estado do Amazonas, que foi considerada por muitos ambientalistas um grande desastre ambiental, deixando muitas espécies de peixes, aves e mamíferos sem habitat e, além disso, fragilizou a floresta em seu entorno e aumentou a emissão de gases do efeito estufa na Amazônia (TELLES; BRAGA, 2004).

Em virtude destes desastres, a sociedade mundial começou a buscar alternativas para frear a intervenção do ser humano no ambiente. Assim, surgiram as grandes Conferências Mundiais, cujo objetivo era alertar os países sobre os impactos que o meio ambiente vinha sofrendo (REIGOTA, 2014).

De tal modo, que, em 1972, ocorreu a primeira Conferência Mundial de Meio Ambiente Humano, em Estocolmo, capital da Suécia. Realizada pela Organização das Nações Unidas ONU, o objetivo deste encontro era sensibilizar a sociedade vigente da época, no intuito de melhorar sua relação com o meio ambiente e, assim, atender às necessidades da população presente sem comprometer as gerações futuras (REIGOTA, 2014). O grande tema em discussão nesta reunião foi a poluição ocasionada, principalmente, pelas indústrias. Porém, inicialmente, alguns países subdesenvolvidos não demonstraram uma real preocupação com os fatos apresentados na conferência, visto que estavam vivendo seus "milagres econômicos com o processo de industrialização, fato este que os fez sair em defesa da poluição" (REIGOTA, 2014, p. 20).

Desta forma, os problemas socioambientais continuaram a agravar-se em todos os continentes. Outras conferências foram realizadas, entre as quais podemos citar a Conferência das Nações Unidas sobre o Meio Ambiente e o Desenvolvimento, ocorrida em 1992, também 
conhecida como Eco-92 ou Rio 92, que teve como objetivo retomar as problemáticas socioambientais presentes no cenário global. Esta conferência diferenciou-se da anterior, pois teve a presença maciça de inúmeros chefes de Estado, a participação da sociedade civil, como também, um grande número de Organizações Não-Governamentais (ONG’s), demonstrando, assim, a importância da questão ambiental, uma vez que esta temática não era mais apenas uma preocupação dos ambientalistas e militantes, mas, também, de toda a comunidade mundial (DIAS, 2004).

Neste sentido, a formação do cidadão e da cidadã para atuar diante dos problemas e desafios ambientais adquiriu "visibilidade pública e a Educação Ambiental deixou de ser conhecida e praticada apenas por uma pequena parte da sociedade" (REIGOTA, 2014, p. 30). Deste modo, a EA, como perspectiva educativa, torna-se primordial a nível global.

Contudo, apesar da EA consolidar-se como um importante meio para a formação de indivíduos conscientes ambientalmente, esta demorou para ganhar espaço no currículo das escolas brasileiras. Foi somente em meados de 1981, quando foi instituída a Política Nacional do Meio Ambiente, que se reconheceu a importância de se trabalhar a temática ambiental no campo educacional. E, em 1988, a Constituição Federal, reforça esta tendência ao destacar, em seu Artigo 225, Inciso VI, que a Educação Ambiental deverá ser “promovida em todos os níveis de ensino" com o desígnio de conscientizar os cidadãos para a preservação e a conservação do meio ambiente (BRASIL, 1988, p. 64).

Em 1999, a Lei No 9.795, dispõe sobre a Educação Ambiental e institui a Política Nacional de Educação Ambiental - PNEA, ressaltando, em seu Artigo 1º, que:

\footnotetext{
Entende-se por Educação Ambiental os processos por meio dos quais o indivíduo e a coletividade constroem valores sociais, conhecimentos, habilidades, atitudes e competências voltadas para a conservação do meio ambiente, bem de uso comum do povo, essencial à sadia qualidade de vida e sua sustentabilidade (BRASIL, PNEA, 1999, p. 1)
}

Tomando como base a descrição de Educação Ambiental acima citada, podemos verificar que a EA é um processo que permeia a construção de valores, atitudes e conhecimentos em prol da conservação do meio ambiente. Destacamos que, em seu Artigo $2^{\circ}$, a PNEA, menciona que a Educação Ambiental é considerada como "um componente essencial e permanente da Educação Nacional, devendo estar presente, de forma articulada, em todos os níveis e modalidades do processo educativo, em caráter formal e não-formal”, para que seja 
possível formar sujeitos críticos e engajados ambientalmente, frente ao desenvolvimento sustentável (BRASIL, PNEA, 1999, p. 1).

No que se refere ao desenvolvimento sustentável, Barbosa $(2008$, p. 1) destaca que este termo surgiu a partir de estudos da Organização das Nações Unidas sobre as "mudanças climáticas, como uma resposta para a humanidade perante a crise social e ambiental, pela qual o mundo passava, a partir da segunda metade do século XX”. Para a ONU, desenvolvimento sustentável é saber utilizar os recursos naturais de forma consciente, sem comprometer as necessidades das futuras gerações.

Neste ínterim, foi criada, em setembro de 2015, a Agenda 2030 para o Desenvolvimento Sustentável, por representantes de 193 Estados Membros da ONU, destacando em seu texto que promover o desenvolvimento sustentável nos próximos 15 anos é uma prioridade global. A "Agenda 2030" foi criada com base nos Objetivos de Desenvolvimento do Milênio, e, atualmente, é considerada uma agenda de alcance e significado sem precedentes. "Ela é aceita por todos os países e é aplicável a todos, levando em conta as diferentes realidades nacionais, capacidades e níveis de desenvolvimento e respeitando as políticas e prioridades nacionais" (ONU, AGENDA 2030, 2015, p. 3).

Um dos principais objetivos propostos pela agenda é sensibilizar a comunidade mundial sobre a importância do desenvolvimento sustentável, tomando como base suas três dimensões: a econômica, a social e a ambiental. Para isto, a Agenda 2030 destaca "17 Objetivos de Desenvolvimento Sustentável (ODS) e 169 metas associadas que são integradas e indivisíveis” (ONU, AGENDA 2030, 2015, p. 7).

A escola torna-se o local onde o conhecimento ambiental deve ser abordado sob uma nova perspectiva, ou seja, ela passa a ser um dos espaços sociais em que a EA deve ser pensada e realizada enquanto um saber. Neste sentido, Leff (2011, p. 144), destaca que:

O saber ambiental surge como um conjunto de paradigmas de conhecimento, de disciplinas científicas, formações ideológicas, sistemas de valores, crenças, conhecimentos e práticas produtivas sobre diferentes processos e elementos, naturais e sociais, que constituem o ambiente, suas relações e seus potenciais (LEFF, 2011, p. 144).

Percebe-se que o autor enfatiza a importância da EA como prática educativa, principalmente, quando destaca os desafios que estes novos paradigmas trazem para a prática docente sobre este novo saber ambiental, pois ele aborda tanto os aspectos ecológicos do meio ambiente, quanto os sociais, econômicos e culturais. 
Neste sentido, para entender a complexidade que engloba o saber ambiental, o professor deve inserir em sua prática pedagógica o ensino da EA, de forma transversal e interdisciplinar, pois, assim, a escola poderá formar alunos que buscam soluções alternativas para os problemas ambientais presentes em sua própria casa, escola, bairro, como também na sociedade, constituindo-se, desta forma, como cidadãos críticos, políticos e autônomos, uma vez que a EA é considerada uma Educação Política (REIGOTA, 2014).

Assim sendo, para formar professores que trabalhem a Educação Ambiental, tomando como base os aspectos sociais e ambientais, é importante que nos cursos de graduação os mesmos tenham contato com práticas formativas concretas, que despertem neles o interesse pela temática, ao mesmo tempo que os sensibilizem sobre a importância de trabalhar a Educação Ambiental de forma emancipatória.

No tópico a seguir, trazemos algumas propostas didáticas no intuito de como trabalhar a Educação Ambiental em espaços não-formais (ENF), tomando como base a formação de futuros professores.

\subsection{Propostas didáticas em Educação Ambiental em ENF}

É de suma importância a utilização de espaços não-formais (ENF), no contexto da Educação Ambiental, pois além destes proporcionarem uma aprendizagem significativa aos educandos, permitem, também, aos mesmos, explorar, observar e analisar o ambiente, com recursos e elementos naturais que, geralmente, não são possíveis de utilizar apenas no espaço formal, isto é, apenas na esfera escolar.

No contexto educacional, os espaços não-formais de ensino podem ser qualquer lugar que permita uma prática educativa, além dos ambientes escolares (JACOBUCCI, 2008). Em relação a sua origem, a expressão "não-formal", deve-se ao vínculo com a crise educacional, ocorrida em meados do século XX, refletindo sobre o papel da escola, numa perspectiva apenas de reprodutora de conhecimentos (MARANDINO, 2017).

Neste sentido, destacamos a complexidade e a importância de explorar os ENF, promovendo práticas educativas que possibilitem novos olhares, acerca do tema explorado. Todavia, a utilização destes espaços requer o planejamento das atividades, relacionando-as com o conhecimento prévio dos estudantes e da realidade que os cercam.

Os ENF podem ser divididos em duas categorias, quer sejam os locais que são institucionalizados e os que não são institucionalizados. No que se refere à primeira categoria, 
isto é, os institucionalizados, podemos definir os mesmos como espaços que possuem uma equipe técnica responsável pelas atividades realizadas e, na segunda categoria, ou os não institucionalizados, incluímos os ambientes naturais e urbanos, que não dispõem de uma estrutura institucional (JACOBUCCI, 2008).

A utilização do ENF pode ser considerada como recursos pedagógicos que complementam a educação formal, gerando motivação e interesse, dinamizando as aulas e estimulando para novas aprendizagens (GHEDIN; GHEDIN; FACHIN-TERÁN, 2014). Por esta razão, as práticas educativas nestes ambientes, suscitam a motivação e um maior interesse por parte dos estudantes. De acordo com Rocha e Fachín-Terán (2014), o trabalho em parceria com os espaços não-formais representam uma ótima oportunidade, além destes proporcionarem muitas contribuições no processo ensino-aprendizagem dos estudantes, em geral.

Nesta perspectiva, ao explorar a Educação Ambiental nestes espaços, evidenciamos que a educação, de modo mais abrangente, é a transformação dos indivíduos a partir daquilo que eles conhecem, sentem e compreendem, de maneira geral, o mundo ao seu redor (MENDONÇA; NEIMAN, 2013). De acordo com os autores, toda educação deveria ser ambiental, uma vez que esta deve ocorrer em três contextos, isto é, no social, no cultural e no natural.

$\mathrm{Na}$ atualidade, questões sobre o meio ambiente são consideradas como problemas urgentes que devem ser resolvidos, para que a vida humana seja preservada, saudável, digna e produtiva (PENTEADO, 2010). Tais problemas precisam ser discutidos no contexto educacional e pensar em novas propostas didáticas na perspectiva da EA, utilizando espaços não-formais, torna-se imprescindível, quando refletimos acerca de questões sobre o meio ambiente, preservação e cuidado com o meio natural.

Neste viés, as práticas pedagógicas, devem contemplar uma educação integradora, onde educadores e educandos sintam-se integrados à sociedade e à natureza e não ao serviço delas (BARCELOS, 2012). A utilização de espaços naturais, na perspectiva da EA, busca não somente uma reflexão, mas também uma maior compreensão dos problemas ambientais enfrentados na atualidade, permitindo novos caminhos e olhares em relação ao meio ambiente e sua preservação. 


\subsection{Metodologias Ativas na Educação Ambiental}

Tornar a aula mais atraente e sair do modelo expositivo, no qual o professor atua como personagem no repasse de conteúdos curriculares é um desafio contínuo. Para Moran (2015), o aprendizado ocorre a partir de problemas e situações reais que muitas vezes serão vivenciados na vida profissional.

As metodologias ativas surgiram com o propósito de ressignificar a forma de lecionar e modificar a posição passiva do estudante para o protagonismo de quem conduz o seu próprio conhecimento. É o aprender mais próximo da vida (MORAN, 2015, p. 18). Na Educação Ambiental, tais metodologias estão centradas em ações que passam pela aprendizagem colaborativa e interdisciplinar e vão proporcionar o protagonismo do aluno (MORAES; CREMER, 2018 p. 180). Segundo estes autores, a geração de ideias auxilia na reflexão e, ao invés de uma ação mecânica de memorização, conduz ao conhecimento.

O Conselho Nacional de Educação, observando as Normativas da Educação, definiu por meio da Resolução 2, de 20 de dezembro de 2019, as novas Diretrizes Curriculares Nacionais para a Formação Inicial de Professores para a Educação Básica (BRASIL, 2019). Assim, no Artigo $8^{\circ}$ da referida Lei é abordado como devem ser os fundamentos pedagógicos para a formação docente e as metodologias ativas têm presença no Inciso II.

Neste contexto, a Base Nacional Comum para a Formação Inicial de Professores da Educação Básica (BRASIL, 2019), apresenta as dimensões do conhecimento profissional, com ênfase no contexto formativo, além da necessidade de se compreender os objetos do conhecimento. Isto desencadeia possibilidades para articular situações socioculturais com os estudantes, conduzindo-os a uma aprendizagem significativa.

Fundamentados nestas premissas, e tendo por proposta criar novas formas ativas de práticas educativas, pensou-se o modelo de uma atividade para a disseminação da EA, tendo uma "Caixa" como elemento facilitador para a condução do roteiro ativo de aprendizado.

\section{METODOLOGIA}

A pesquisa apresenta uma abordagem qualitativa descritiva. Para o caminho metodológico adotamos como marco conceitual autores como Minayo (2007), Bauer e Aarts (2015), Bardin (2018) e Merleau-Ponty (2018).

Analisar a realidade, tendo o cotidiano e a vivência das pessoas como ambiente da investigação, remete-nos à esfera dos significados, como ressalta Minayo (2007 p. 21), ao 
descrever que "o universo da produção humana, que pode ser resumido no mundo das relações, das representações e da intencionalidade, é objeto da pesquisa qualitativa". Ratificando o entendimento da autora, compreendemos ser o ato de pensar e agir dos participantes, deste estudo, o ponto principal para a consolidação de nosso objetivo de pesquisa.

Os participantes desta pesquisa constituíram um grupo de 58 estudantes, sendo 32 oriundos do turno matutino e 26 do horário noturno, da disciplina de Educação Ambiental, do curso de graduação em Pedagogia, de uma Instituição Pública de Ensino Superior de Manaus, Amazonas. De acordo com Minayo (2007, p. 63), "os sujeitos/objetos da investigação, primeiramente, são construídos, teoricamente, enquanto componentes do objeto de estudo". A partir do entendimento da autora, ressaltamos que os participantes foram essenciais para a realização do estudo, mediante o relato escrito de cada um na prática realizada.

A fundamentação filosófica foi norteada nas premissas de Merleau-Ponty (2018), sobre a percepção e o processo de captar no ambiente o sentido das coisas e da experiência de vida, de quem está envolvido no contexto estudado. Merleau-Ponty (2018, p. 576), nos diz que "o sujeito é inseparável do mundo, mas de um mundo que ele mesmo projeta".

O local escolhido para a aplicação da prática foi o Bosque da Ciência, do Instituto Nacional de Pesquisas da Amazônia - INPA, um fragmento da floresta amazônica, instalado na zona urbana da capital amazonense, onde é possível associar o lazer e o entretenimento com a pesquisa desenvolvida por cientistas em um espaço não-formal institucionalizado (OLIVEIRA; FACHÍN-TERÁN, 2019).

O instrumento usado para a coleta de dados foi a atividade denominada "Caixa da Natureza", desenvolvida a partir de um modelo originado em um curso de multiplicadores de Educação Ambiental, ofertado pelo Centro Nacional de Pesquisa e Conservação da Biodiversidade Amazônica - CEPAM, vinculado ao Instituto Chico Mendes de Conservação da Biodiversidade - ICMBio). Assim, uma caixa de papelão foi confeccionada, decorada e posicionada em um lugar estratégico para que, ao fim da atividade, os participantes pudessem deixar o papel com suas respostas individuais. Após percorrerem os ambientes do BC, cada um dos participantes respondeu à seguinte pergunta "Qual a relação que você fez do ambiente do Bosque da Ciência com sua infância?’. Posteriormente, todas as respostas foram usadas como base para a análise desta investigação.

Através das representações das falas dos entrevistados, chegamos à composição do corpus desta pesquisa, transformando-o na evidência coletada para a argumentação do estudo (BAUER; AARTS, 2015, p. 39). A partir das respostas dos participantes, optamos pela forma 
clássica de análise de conteúdo "com grelha de análises categorial, privilegiando a repetição de frequência dos temas, com todas as entrevistas juntas" (BARDIN, 2018, p. 91). Seguimos os procedimentos adotados pela autora e iniciamos o tratamento das falas pela pré análise, seguida pela exploração do material, do tratamento das informações coletadas e da interpretação com o estabelecimento das categorias, na qual definimos quatro: recordação, afetividade, aprendizado e associação.

\subsection{Percurso de Campo}

Todos os participantes receberam um guia da prática, no qual constava um breve referencial teórico sobre a Educação Ambiental e, ainda, o uso dos espaços educativos como ambientes facilitadores do aprendizado. A respeito da elaboração de um manual, este tem a função de orientar o estudante sobre como realizar a prática, de forma clara e objetiva (SANTOS, 2018, p. 210). E, para tornar a atividade ainda mais interessante, os estudantes foram motivados à participação, logo na entrada do Bosque da Ciência, após todos ouvirem as orientações a falarem sobre suas expectativas em uma roda de conversa introdutória. Em seguida, iniciaram a observação do ambiente traçado para o exercício, com o propósito de relacionar os elementos da natureza com situações que remetessem à infância de cada um, com base nas vivências que tiveram com a floresta amazônica.

Os monitores da prática estiveram presentes ao longo de toda a atividade, a fim de esclarecer dúvidas e apoiar os participantes em toda a extensão do percurso. A proposta foi deixá-los livres para agir, sozinhos, durante a observação. Somos capazes de inferir que o momento de interação da pessoa com o ambiente é marcado pelo "sentir", assim expresso por Merleau-Ponty (2018):

O sentir é esta comunicação vital com o mundo que o torna presente para nós como lugar familiar de nossa vida. É a ele que o objeto percebido e o sujeito que percebe devem sua espessura. Ele é o tecido intencional que o esforço de conhecimento procurará decompor (MERLEAU-PONTY, 2018, p. 84).

Na primeira etapa da observação, os participantes percorreram o Parque Aquático Robin Best, cujo nome veio do pesquisador que estudou mamíferos aquáticos durante muitos anos na Amazônia. No local, conheceram as espécies de mamíferos da fauna amazônica ameaçadas de 
extinção, entre os quais a ariranha (Pteronura brasiliensis) e o Peixe-Boi-da-Amazônia (Trichechus inunguis).

Posteriormente, visitaram a Casa da Ciência e a exposição fixa, intitulada "Tramas da Ciência", montada a partir de uma cooperação entre o INPA e a Universidade de Quioto, no Japão, onde de forma livre, percorreram as salas do local. Na Casa da Ciência conheceram ambientes como a sala dos sons, um espaço escuro, onde o visitante entra para ouvir ruídos e tem a sensação de estar no ambiente natural. Além disso, foi possível ouvir o coaxar de sapos e grilos, o canto de alguns pássaros e o sonido de raios e trovões com o cair da chuva.

De forma livre, os participantes puderam percorrer trilhas do Bosque da Ciência para consolidar o momento final da prática. Este caminhar em silêncio é descrito como uma prática de contato com a natureza pelo autor Cornell (2008), que elaborou modelos de abordagens educativas, tendo a natureza como elemento facilitador. Embora seja um estudo específico para crianças, vamos adotá-lo, também, em alguns momentos desta pesquisa para relatar o contato dos sujeitos com a floresta.

\section{ANÁLISE E RESULTADOS}

Ao relacionar o silêncio e a harmonia que o caminhar traz para o aprendizado, Cornell relata que este "desperta em nós a sensação de que estamos compartilhando o mundo com todos os seres vivos" (CORNELL, 2008, p. 179). Após percorrerem o trajeto sugerido, os participantes puderam escrever o que sentiram (Tabela 1). Abaixo, apresentamos uma amostra das respostas dadas pelos estudantes (E) tal como esta foi registrada: 
Tabela 1 - Relatos dos alunos sobre a relação de lembranças do ambiente do Bosque da Ciência com sua infância

\begin{tabular}{c|c|l}
\hline Pergunta feita: Qual a relação que você fez do ambiente do Bosque da Ciência com sua infância? \\
\hline Categorias & $\begin{array}{c}\text { Quantidade de } \\
\text { citações }\end{array}$ & \multicolumn{1}{c}{ Amostra de respostas } \\
\hline Recordação & 23 & $\begin{array}{l}\text { "O ambiente calmo da natureza me recorda os passeios da } \\
\text { minha infância, incluindo o próprio Bosque da Ciência". } \\
\text { (E04) }\end{array}$ \\
\hline Afetividade & 18 & $\begin{array}{l}\text { "De tudo o que mais me lembrou algo da infância foi a } \\
\text { sensação de paz, de conexão com a natureza, há muito } \\
\text { tempo perdida, esquecida. Aquele tempo que você tira } \\
\text { apenas para apreciar, nesse mundo em que é tão corrido, } \\
\text { nos esquecemos do que é belo, grátis e nosso". } \\
\text { (E18) }\end{array}$ \\
\hline Aprendizado & 13 & $\begin{array}{l}\text { "A visita ao peixe-boi em que realizei a minha primeira } \\
\text { visitação ao INPA com o meu irmão e que ele me explicou } \\
\text { a importância de não jogar lixo nos rios". } \\
\text { (E01) }\end{array}$ \\
\hline Associação & 03 & $\begin{array}{l}\text { "As árvores finas, com tons de marrom e pintas verdes, me } \\
\text { lembram as várias vezes que fui ao Parque do Mindu, meu } \\
\text { primeiro contato com a natureza. Eu costumava imaginar } \\
\text { como a floresta era antes da cidade existir onde havia } \\
\text { concentração de tal árvore". } \\
\text { (E24) }\end{array}$ \\
\hline
\end{tabular}

Fonte: Elaborado pelos autores (2020).

A fim de favorecer o detalhamento dos relatos, os resultados serão apresentados mediante o traçado de cada categoria identificada na análise do conteúdo apresentado.

\subsection{Categorias}

\subsubsection{Recordação}

Sobre a recordação, Gauer e Gomes (2008, p. 507), abordam após a leitura de vários teóricos, determinando o mesmo a evocação, a situações pessoais estabelecidas no passado, relacionando-as às histórias de vida das pessoas. Estando, portanto, o ato de recordar envolvido em várias habilidades cognitivas relacionadas à memória autobiográfica e, todos estes eventos, relatam os autores, foram marcantes na vida das pessoas.

O uso de um ambiente natural possibilitou a imersão em momentos agradáveis que remeteram às experiências vividas na fase da infância, viabilizando o afloramento de lembranças guardadas na memória de muitos participantes. Freire (2019), ao abordar a relação da história do sujeito no processo de Educação nos diz que olhar para trás não é um momento apenas de nostalgia, mas sim, "um modo de melhor conhecer o que está sendo, para melhor 
construir o futuro" (FREIRE, 2019, p. 103). Quando o autor fala sobre voltar ao passado ele refere-se à construção de um novo olhar, tendo por sustentação a história de vida do indivíduo como base em uma experiência sólida que possibilite um olhar mais crítico para o momento atual, tendo o passado como referência na construção deste novo saber. É a realidade histórica a base da experiência que remete à recordação. Podemos observar esta associação, entre teoria e prática, na seguinte transcrição: "O passeio trouxe lembranças de quando eu passeava com minha família e tudo era novo e diferente" (E7).

Aqui, as palavras expressam o momento em que o contato com a natureza sensibilizou a pessoa. O vínculo prazeroso é descrito por Cornell (2008), quando o autor menciona que a natureza deve ser aproveitada para o desenvolvimento de experiências alegres, cujo ambiente seja um espaço educador (CORNELL, 2008, p. 20). Além disso, refletindo sobre a necessidade de sair do individual para projetar o coletivo, lembramos o pensamento de Marandino (2017), quando esta autora fala das práticas em espaços não-formais, nas quais as pessoas são levadas a ponderar soluções de problemas coletivos, avaliando situações pessoais que possam ser relacionadas neste contexto global de sustentabilidade ambiental.

Ao exteriorizar sobre um momento vivido no passado, a personagem do estudo nos conduz ao entendimento que Reigota (2002, p. 123) tem do processo pedagógico na Educação Ambiental, no qual é importante as várias leituras e interpretações do mundo, sendo o diálogo o ápice do aprendizado. O diálogo foi apresentado em forma escrita, no relato do momento vivido, visão esta, alinhada com o pensamento freiriano.

Analisando outro depoimento surge a inclusão dos sentidos humanos nesta relação com o ambiente: "O som dos pássaros me remete à casa da minha vó no interior. Eu ia todos os finais de semana para dormir lá e acordava com o som dos pássaros” (E15).

Santos (2018, p. 202), ao descrever o quanto a prática de campo é importante para a formação no Ensino Superior, nos diz que este tipo de atividade engloba todos os sentidos humanos "para captar e apreender informações dos ambientes visitados, considerando também o conhecimento, previamente, adquirido pelo estudante". O contexto preexistente, relatado pela autora neste tipo de metodologia ativa, é baseado na própria experiência do estudante. Assim, ao caminhar na mata, ouvir o som dos pássaros, a sensibilização ocorreu por meio de uma recordação auditiva que remeteu a pessoa aos momentos de uma relação prazerosa com seus avôs na época da infância. Em outro relato, destacamos a observação e o ato silencioso de caminhar nas trilhas na floresta: 
Ao olhar o galho da goiabeira, lembrei das tardes que passava no sítio da minha familia, subindo em árvores, vendo a mata fechada e uma casinha de madeira, lembrei de quando eu ia a casa do meu tio, no Tarumã, sítio do meu avô. Vendo o peixinho, lembrei dos dias que ia ao igarapé para tomar banho e brincar e me divertir. O som das cigarras (desenho de coração). A castanha (fruta) me fez lembrar de quando fazíamos "medo" para nós de não passar por baixo da árvore, porque ela poderia cair na nossa cabeça. O bicho preguiça lembrei de quando ele passava no meio da rua e esperávamos ele passar" (E23).

Constata-se a riqueza de detalhes descritos pela pessoa, inclusive com a elaboração de desenhos, como de um coração, para expressar o quanto o som do inseto cigarra (Cicadoidea) tinha significado em suas recordações. Cornell (2008, p. 181), nos diz que "ao observarmos a natureza em silêncio, descobrimos dentro de nós uma afinidade com tudo que vemos - plantas, animais, pedras, terra e céu" - e foi exatamente isto que verificamos com quem escreveu este relato, pois vários elementos da natureza, como a árvore da Goiabeira (Psidium guajava), os peixes, o som emitido pela cigarra e animais como a preguiça fluíram na relação de recordação do ambiente natural com a história de vida pessoal de quem escreveu.

\subsubsection{Afetividade}

Ao estabelecermos a afetividade como relação no processo de aprendizagem baseamonos na relação estreita desta com as experiências pessoais relacionadas ao prazer, a alegria e a satisfação de estar em contato com o ambiente natural. Salla (2011), ao abordar o termo referese ao conceito do teórico Henry Wallon, no qual a afetividade está relacionada à capacidade. A afetividade, em conjunto com a cognição e a motricidade, conduz ao processo de desenvolvimento e conhecimento (SALLA, 2011, p. 1), como podemos observar na descrição a seguir:

Nossa! Que inesquecivel. Lembrei de quando íamos de barco para o interior do interior em uma comunidade bem longe da cidade. Lá a gente andava de pé no chão, chão de terra, com muitas árvores em volta, e o único barulho era dos bichos. O nome do lugar é Xiborena ou Chiborena. E a gente só chegava lá de barco. Isso faz muito, muito tempo (desenho de coração)" (E20).

A pessoa inicia o relato com uma interjeição, demostrando, claramente, a situação de deslumbramento ante a relação feita entre o ambiente do Bosque da Ciência com a vida que teve em uma localidade do interior do Amazonas quando criança, na qual tece a experiência de andar descalça e sentir o pé no chão, dando ênfase ao fato do caminhar ser em terra e não em 
estrutura pavimentada. Cornell (2008, p. 176), releva em seu estudo ser necessário entrar no ambiente natural "com o coração aberto, permitindo que esplêndidas experiências nos surpreendam".

Na condição de adultos, enfatiza Cornell (2008, p. 21), que acalentar lembranças é um fato que mostra o quanto aqueles momentos vividos foram profundos na vida das pessoas. Como demonstra o relato abaixo:

Na minha infância tive a oportunidade de crescer em meio à natureza. O ambiente do Bosque da Ciência me faz lembrar de quando eu era criança e brincava subindo árvores, correndo com os amigos. A sensação de respirar um ar mais puro e a liberdade que traz este lugar também remete a minha infância" (E41).

\subsubsection{Aprendizado}

A fim de conduzir nossa abordagem sobre aprendizagem, assentamos este estudo na concepção de Moreira (2011, p. 13), para a definição de aprendizagem significativa, entendida pelo autor, como a interação das ideias expressas, simbolicamente, com aquilo que o aprendiz já sabe. É oportuno esclarecer que o conhecimento adquirido de forma relevante já existe na estrutura cognitiva da pessoa e vai corroborar no processo de aprendizado. Freire (2019, p. 99), nos fala da reflexão de mundo, a partir de experiências passadas, e de como a análise espelha e aumenta o campo de percepção da pessoa. Fato este, presente no relato a seguir: "O fato de respirar a natureza e sentir outras vibrações me remetem à infância aventureira, perdida pelo caos urbano e "necessário'”, (E9).

$\mathrm{Na}$ contextualização temos evidenciada a reflexão de quem escreveu. Em uma destacase o "caos urbano" em contraposição com o ambiente natural que, apesar da crítica, há um conformismo, pois remete à desordem urbana como sendo algo necessário. Corroborando tal fato, destacamos Freire (2019, p. 98), em sua fala: "quanto mais se problematizam os educandos, como seres do mundo e com o mundo, tanto mais se sentirão desafiados". Barbosa (2008), nos lembra que o desafio da sustentabilidade ambiental é a conscientização, cujo processo deve ser percorrido, continuamente.

Além disso, é possível, ainda, aprender e estabelecer laços de comunhão com a natureza, possibilitando, inclusive, a percepção de que só em um meio ambiente preservado e estável, como nos fala Cornell $(2008$, p. 21), há a comunhão direta com a natureza por meio do toque, olfato, paladar, visão e som. 


\begin{abstract}
"Durante a minha infância havia a casa de um parente que eu frequentava aqui na cidade de Manaus que parecia um sitio de tantas árvores frutiferas e natureza ao redor. Na maior parte do tempo eu subia nas árvores, me agarrava nos galhos, colhia frutos e comia. Visitando o bosque, o ambiente me remete a esses tempos e de como é importante a preservação desse espaço, já que o meio urbano é tudo o que conhecemos agora. Para as crianças é de suma importância conhecer esses ambientes" (E44).
\end{abstract}

\title{
4.1.4 Associação
}

O dicionário nos traz o conceito de associação como sendo a aproximação, a conexão, a relação de algo. Se usarmos a teoria da aprendizagem significativa do teórico David Ausubel, relatada por Moreira (2011, p. 28), estabeleceremos os subsunçores como os conhecimentos prévios relevantes para a aprendizagem de outros conhecimentos. Diante do fato que os sujeitos associaram elementos vistos no Bosque da Ciência com algo que já tinham visto anteriormente, em algum momento de suas vidas, podemos estabelecer a relação da categoria criada com a teoria na qual a aprendizagem é baseada na experiência das pessoas, transformando aquele conhecimento mais significativo a partir do momento que está embasado em vivências passadas. Assim, ao discorrer sobre esta criticidade, acende-se a discussão sobre o quanto a vivência com o meio ambiente é necessária para dar ao indivíduo o referencial comparativo necessário para a noção do impacto que a vida sem o verde tem no cotidiano das pessoas. Como reflete o relato abaixo:

\footnotetext{
"Nunca estive no Bosque da Ciência (hoje foi minha primeira vez), mas olhando as árvores, as pequenas trilhas, o cheiro de ar puro, relembra quando eu tinha entre 5 e 6 anos e meus pais me levaram ao zoológico e o ambiente com as suas semelhanças, me trouxe recordações, pois quase todo final de semana eu estava lá e era meu ambiente preferido". (E53).
}

O ápice da prática, após o percurso nas trilhas do Bosque da Ciência, foi o momento da roda de conversa, com a participação de todos que desejassem manifestar a experiência vivida naquele dia. Santos (2018, p. 209), apresenta o momento do diálogo como sendo fundamental para a aprendizagem ativa. E o que vimos foram muitas manifestações, demonstrando mudanças de comportamento a partir da visita. Eis algumas respostas tais como foi registrado em roda de conversa: 


\footnotetext{
"Na verdade, eu nunca tinha visto a natureza do modo como vocês apresentaram hoje aqui para a gente, do ensino, da aprendizagem. Quando tem a oportunidade passo dois ou três dias com a natureza, mas agora com um novo olhar".

"Vê o livro e vir a um lugar, assim, é ver a teoria na prática acontecendo. É mais prazeroso. E puxa o sentimento de sensibilizar”.

"A gente está aqui nesse verde muito grande, ali tem uma exposição que o homem pode fazer com toda essa natureza e fazer essa relação nos faz refletir sobre nossas ações.
}

É perceptível a mudança de perspectiva dos participantes após a prática vivenciada no Bosque da Ciência. Seguramente, poderão tornar-se futuros professores mais sabedores da necessidade que tem de uma Educação Ambiental mais presente no cotidiano do aprendiz. $\mathrm{Na}$ prática estabelecida no Bosque da Ciência a infância foi a motivadora deste instrumento de percepção. E a visão após a atividade é o resultado da energia que impulsionou o saber.

\section{CONSIDERAÇÕES}

Sobre o estudo apresentado, salientamos que o mesmo constituiu-se em uma proposta, no intuito de contribuir para a formação de professores, a partir da criação de uma prática ativa de aprendizagem, na qual a perspectiva da construção do saber ocorreu por meio da reflexão com o mundo percebido. Nosso objetivo nesta pesquisa foi entender como ocorria a difusão da Educação Ambiental nos espaços educacionais, usando, para isto, uma atividade de campo, a qual designamos como "Caixa da Natureza".

Os resultados corroboram com o Artigo $2^{\circ}$, da Resolução do Conselho Nacional de Educação, de Número 2, publicada em 20 de dezembro de 2019. No documento que estabelece as Diretrizes Curriculares Nacionais para a Formação Inicial de Professores está descrito o desenvolvimento do estudante com base em aprendizagens essenciais, onde se desenvolvam os aspectos intelectual, social e emocional da formação, a fim de se promover uma educação integral.

Sobre o relato apresentado, a relação dos estudantes com as experiências da infância motivou sentimentos e gestos de preocupação com a conservação ambiental, bem como com a preservação do meio ambiente para as futuras gerações. Percebemos com a experiência que o contato com a natureza fez com que os estudantes tivessem interações prazerosas e repensassem suas ações.

A partir da análise dos resultados, salientamos que a prática permitiu difundir a 
Educação Ambiental e alertar para a importância do ambiente natural na vida das pessoas. A utilização desta técnica de coleta mostrou-nos ser possível usar o procedimento na formação continuada dos cursos que envolvem licenciaturas.

No final deste estudo, esperamos, portanto, ter colaborado com as práticas de ensino, onde a vivência das pessoas seja o caminho para promover o diálogo, ampliando, com isso, a percepção e a sensibilização ambiental.

\section{REFERÊNCIAS}

BARBOSA, Gisele Silva. O desafio do desenvolvimento sustentável. Revista Visões. v. 1. n. 4. p. 1-11. jan/jun, 2008. Disponível em:

http://www.fsma.edu.br/visoes/ed04/4ed O Desafio Do Desenvolvimento Sustentavel Gis ele.pdf. Acesso em: 05 out. 2020.

BARDIN, Laurence. Análise de conteúdo. 5. ed. Tradução de Luís Antero Rosa e Augusto Pinheiro. Lisboa: Edições 70, 2018.

BAUER, Martin W; AARTS, Bas. A construção do corpus: um princípio para a coleta de dados qualitativo. In: BAUER, M.W.; GASKELL. G. Pesquisa qualitativa com texto, imagem e som: um manual prático. Tradução de Pedrinho Guareschi. 13 ed. $3^{\mathrm{a}}$ reimpressão. Petrópolis, RJ: Vozes, 2015. p. 39-63.

BARCELOS, Valdo. Educação Ambiental: sobre princípios, metodologias e atitudes. 4. ed. Petrópolis, RJ: Vozes, 2012.

BRASIL. Constituição Federal. Artigo 225. Inciso VI. Brasília: 1988.

BRASIL. Conselho Nacional de Educação. Resolução CNE/CES. N 2, de 20 de dezembro de 2019. Diretrizes Curriculares Nacionais para a Formação Inicial de Professores para a Educação Básica. Institui a Base Nacional Comum para a Formação Inicial de Professores da Educação Básica (BNC-Formação). Brasília: Diário Oficial da União, 23/dez, 2019.

BRASIL. Lei No 9.795, de 27 de abril de 1999. Dispõe sobre a Educação Ambiental. Institui a Política Nacional de Educação Ambiental e dá outras providências. Diário Oficial da União, Brasília. p. 1. Abril. 1999.

CORNELL, Joseph. Vivências com a natureza. Tradução: Arianne Brianezi, Cláudia Perusso Nardi, Júlia Dohas, Rita Mendonça. 3. ed. São Paulo: Aquariana, 2008.

DIAS, Genebaldo Freire. Educação Ambiental: princípios e práticas. 9. ed. São Paulo: Gaia, 2004.

FREIRE, Paulo. Pedagogia do oprimido. 67. ed. São Paulo: Paz e Terra, 2019. 
GAUER, Gustavo; GOMES, William Barbosa. Recordação de eventos pessoais: memória autobiográfica, consciência e julgamento. Psicologia: Teoria e Pesquisa, Brasília. v. 24. n. 4. p. 507-514. Dez. 2008. Disponível em: https://www.scielo.br/scielo.php?pid=S010237722008000400014\&script=sci abstract\&tlng=pt. Acesso em: 17 out. 2020.

GHEDIN, Leila Maria; GHEDIN, Iliane Margarete; FACHÍN-TERÁN, Augusto. Análise Diagnóstica dos tipos de placas e seu uso na educação científica em espaços não-formais da cidade de Manaus. In: FACHÍN-TERÁN, A.; SANTOS, S.C.S. (Orgs.). Ensino de Ciências em Espaços Não-Formais Amazônicos. Curitiba: CRV, 2014. p. 55-58.

JACOBUCCI, Daniela Franco Carvalho. Contribuições dos espaços não-formais de Educação para a formação da cultura científica. Em extensão. Uberlândia. v. 7. p. 55-66. 2008.

Disponível em: http://www.seer.ufu.br/index.php/revextensao/article/view/20390/10860. Acesso em: 29 out. 2020.

LEAL, Edvalda Araújo; MIRANDA, Gilberto José; CASA NOVA, Silvia Pereira Castro. Revolucionando a sala de aula: como envolver o estudante aplicando técnicas de metodologias ativas de aprendizagem. São Paulo: Atlas, 2018.

LEFF, Enrique. Saber ambiental: sustentabilidade, racionalidade, complexidade, poder. Petrópolis: Vozes, 2011.

OLIVEIRA, Ercilene Nascimento Silva; FACHÍN-TERÁN, Augusto. Bosque da Ciência. 2020; Tema: Parques de Manaus. Disponível em:

https://ensinodeciencia.webnode.com.br/parques/. Acesso em: 06 out. 2020.

MARANDINO, Martha. Faz sentido ainda propor a separação entre os termos educação formal, não formal e informal? Ciência\&Educação (Bauru). v. 23. n. 4. p. 811-816. 2017. Disponível em: https://www.scielo.br/pdf/ciedu/v23n4/1516-7313-ciedu-23-04-0811.pdf. Acesso em: 30 de out. 2020.

MENDONÇA, Rita; NEIMAN, Zysman. A natureza como educadora: transdisciplinaridade e Educação Ambiental em atividades extraclasse. 2. ed. São Paulo: Aquariana, 2013.

MERLEAU-PONTY, Maurice. Fenomenologia da percepção. Tradução de Carlos Alberto R. de Moura. 5. ed. São Paulo: Martins Fontes, 2018.

MINAYO, Maria Cecília Souza; DESLANDES, Suely Ferreira; GOMES, Romeu. Pesquisa social: teoria, método e criatividade. 26. ed. Petrópolis, RJ: Vozes, 2007.

MORAN, José. Mudando a educação com metodologias ativas. In: Convergências

Midiáticas, Educação e Cidadania: aproximações jovens. Coleção Mídias

Contemporâneas. 2015. Disponível em: http://www2.eca.usp.br/moran/wp-

content/uploads/2013/12/mudando moran.pdf. Acesso em: 19 out. 2020.

MORAES, Ana Carolina de; CREMER, Marta Jussara. Metodologias ativas para ações de Educação Ambiental: um comparativo das metodologias fundamentadas na problematização. In: JUSTUS, Michélle Barreto. Ensino, pesquisa e realizações [recurso eletrônico. Ponta Grossa, PR: Atena Editora, 2018.]. p. 178-193. Disponível em: 
https://www.finersistemas.com/atenaeditora/index.php/admin/api/artigoPDF/4431. Acesso em: 07 out. 2020.

MOREIRA, Marco Antônio. Aprendizagem Significativa: a teoria e textos complementares. São Paulo: Livraria da Física, 2011.

ONU. Organização das Nações Unidas. Transformando Nosso Mundo: A Agenda 2030 para o Desenvolvimento Sustentável. 2015. Disponível em: http://www.agenda2030.com.br/. Acesso em: 07 out. 2020.

PENTEADO, Heloisa Dupas. Meio Ambiente e formação de professores. 7. ed. São Paulo: Cortez, 2010.

REIGOTA, Marcos. A floresta e a escola: por uma Educação Ambiental pós-moderna. 3. ed. São Paulo: Cortez, 2002.

REIGOTA, Marcos. O que é Educação Ambiental. Coleção Primeiros Passos. São Paulo: Brasiliense, 2014.

ROCHA, Sonia Cláudia Barroso; FACHÍN-TERÁN, A. Ensino de Ciências num Espaço NãoFormal Amazônico. In: FACHÍN-TERÁN, Augusto; SANTOS, Saulo Cézar Seiffert (Orgs). Ensino de Ciências em Espaços Não-Formais Amazônicos. Curitiba: CRV, 2014. p. 113126.

RUFINO, Bianca; CRISPIM, Cristina. Breve resgate histórico da Educação Ambiental no Brasil e no mundo. VI Congresso Brasileiro de Gestão Ambiental. Porto Alegre, 2015. Disponível em: https://www.ibeas.org.br/congresso/Trabalhos2015/VII-069.pdf. Acesso em: 27 out. 2020.

SALLA, Fernanda. O Conceito de afetividade de Henry Wallon. Disponível em: https://novaescola.org.br/conteudo/264/0-conceito-de-afetividade-de-henriwallon?gclid=CjwKCAjwrKr8BRB EiwA7eFaphH4Ftu7HrewA9tMUaAOsIqRhT9W R6Ry -JZ4TyJOr2aWsRVDL65XhoC3rgQAvD_BwE. Acesso em: 17 out. 2020.

SANTOS, Nálbia Araújo. Prática de campo: desenvolvendo uma atitude científica nos estudantes. In: LEAL, Edvalda Araújo; MIRANDA, Gilberto José; CASA NOVA, Silvia Pereira Castro. Revolucionando a sala de aula: como envolver o estudante aplicando técnicas de metodologias ativas de aprendizagem. $2^{\mathrm{a}}$ reimpressão: São Paulo: Atlas, 2018. p. 202-213.

TELLES, Telles; BRAGA, Celdo. Meio ambiente: educação e qualidade de vida. Manaus: Edições Kintaw, 2004. 


\title{
NOTAS
}

\begin{abstract}
AGRADECIMENTOS
À FAPEAM, pelas bolsas de estudo concedidas à Ercilene do Nascimento Silva De Oliveira e Sammya Danielle Florencio dos Santos. À Danny Neisel Lima Gutarra, pela tradução do resumo ao Inglês. À Carmem Lúcia Moura Machado, pela revisão ortográfica e textual.
\end{abstract}

\section{FINANCIAMENTO}

Não se aplica.

\section{CONTRIBUIÇÕES DE AUTORIA}

Resumo/Abstract/Resumen: Ercilene do Nascimento Silva de Oliveira, Sammya Danielle Florencio dos Santos, Fabrícia Souza da Silva e Augusto Fachín Terán

Introdução: Ercilene do Nascimento Silva de Oliveira, Sammya Danielle Florencio dos Santos, Fabrícia Souza da Silva e Augusto Fachín Terán

Referencial teórico: Ercilene do Nascimento Silva de Oliveira, Sammya Danielle Florencio dos Santos, Fabrícia Souza da Silva e Augusto Fachín Terán

Análise de dados: Ercilene do Nascimento Silva de Oliveira, Sammya Danielle Florencio dos Santos, Fabrícia Souza da Silva e Augusto Fachín Terán

Discussão dos resultados: Ercilene do Nascimento Silva de Oliveira, Sammya Danielle Florencio dos Santos, Fabrícia Souza da Silva e Augusto Fachín Terán

Conclusão e considerações finais: Ercilene do Nascimento Silva de Oliveira, Sammya Danielle Florencio dos Santos, Fabrícia Souza da Silva e Augusto Fachín Terán

Referências: Ercilene do Nascimento Silva de Oliveira, Sammya Danielle Florencio dos Santos, Fabrícia Souza da Silva e Augusto Fachín Terán

Revisão do manuscrito: Ercilene do Nascimento Silva de Oliveira, Sammya Danielle Florencio dos Santos, Fabrícia Souza da Silva e Augusto Fachín Terán

Aprovação da versão final publicada: Ercilene do Nascimento Silva de Oliveira, Sammya Danielle Florencio dos Santos, Fabrícia Souza da Silva e Augusto Fachín Terán

\section{CONFLITOS DE INTERESSE}

Os autores declararam não haver nenhum conflito de interesse de ordem pessoal, comercial, acadêmico, político e financeiro referente a este manuscrito.

\section{DISPONIBILIDADE DE DADOS DE PESQUISA}

O conjunto de dados que dá suporte aos resultados da pesquisa foi publicado no próprio artigo.

\section{CONSENTIMENTO DE USO DE IMAGEM}

Não se aplica.

\section{COMO CITAR - ABNT}

OLIVEIRA, Ercilene do Nascimento Silva de; SANTOS, Sammya Danielle Florencio dos; SILVA, Fabrícia Souza da; FACHÍN-TERÁN, Augusto. Caixa da Natureza: uma proposta para a educação ambiental em espaços nãoformais. REAMEC - Rede Amazônica de Educação em Ciências e Matemática. Cuiabá, v. 9, n.1, e21020, janeiro-abril, 2021. DOI: 10.26571/reamec.v9i1.11419.

\section{COMO CITAR - APA}

OLIVEIRA, E.N.S; SANTOS, D.F.; SILVA, F.S., \& FACHÍN-TERÁN, A. (2021). Caixa da Natureza: uma proposta para a educação ambiental em espaços não-formais.. REAMEC - Rede Amazônica de Educação em Ciências e Matemática, 9 (1), e21020. DOI: 10.26571/reamec.v9i1.11419.

\section{LICENÇA DE USO}

Licenciado sob a Licença Creative Commons Attribution-NonCommercial 4.0 International (CC BY-NC 4.0). Esta licença permite compartilhar, copiar, redistribuir o manuscrito em qualquer meio ou formato. Além disso, permite adaptar, remixar, transformar e construir sobre o material, desde que seja atribuído o devido crédito de autoria e publicação inicial neste periódico. 


\section{DIREITOS AUTORAIS}

Os direitos autorais são mantidos pelos autores, os quais concedem à Revista REAMEC - Rede Amazônica de Educação em Ciências e Matemática - os direitos exclusivos de primeira publicação. Os autores não serão remunerados pela publicação de trabalhos neste periódico. Os autores têm autorização para assumir contratos adicionais separadamente, para distribuição não exclusiva da versão do trabalho publicada neste periódico (ex.: publicar em repositório institucional, em site pessoal, publicar uma tradução, ou como capítulo de livro), com reconhecimento de autoria e publicação inicial neste periódico. Os editores da Revista têm o direito de proceder a ajustes textuais e de adequação às normas da publicação.

\section{PUBLISHER}

Universidade Federal de Mato Grosso. Programa de Pós-graduação em Educação em Ciências e Matemática (PPGECEM) da Rede Amazônica de Educação em Ciências e Matemática (REAMEC). Publicação no Portal de Periódicos UFMT. As ideias expressadas neste artigo são de responsabilidade de seus autores, não representando, necessariamente, a opinião dos editores ou da referida universidade.

\section{EDITOR}

Marcel Thiago Damasceno Ribeiro

\section{HISTÓRICO}

Submetido: 14 de novembro de 2020.

Aprovado: 08 de janeiro de 2021.

Publicado: 29 de janeiro de 2021. 